\title{
Conhecimento especializado de futuros professores da educação infantil e dos anos iniciais quanto às dificuldades de aprendizagem de alunos cegos e videntes sobre paralelismo
}

Silvania Couto

silvaniacoutoc@gmail.com

orcid.org/0000-0003-3206-794X

Universidade Federal de Sergipe (UFS),

São Cristóvão, Sergipe, Brasil

Miguel Ribeiro

cmribas78@gmail.com

orcid.org/0000-0003-3505-4431

Orcid.org/0000-0003-3505-4431

(Unicamp), Campinas, São Paulo, Brasil

\begin{abstract}
RESUMO
O presente texto traz a análise das produções resultantes da dinamização de uma tarefa que simulava um ambiente inclusivo, discutindo-se o conhecimento revelado por futuros professores da Educação Infantil e dos Anos Iniciais sobre as dificuldades de aprendizagem de alunos cegos e videntes sobre paralelismo. Esse conhecimento do professor é entendido na perspectiva do Mathematics Teachers' Specialized Knowledge, que o conceitualiza como especializado e refere-se a ele como um recurso indispensável à prática docente. Os resultados demonstram que o conhecimento dos futuros professores abrange saber que a habilidade da apreensão operatória mereológica é um recurso potencial para a aprendizagem do paralelismo, tanto para alunos cegos quanto para os videntes, e que identificar paralelismo não implica em saber representá-lo.
\end{abstract}

PALAVRAS-CHAVE: Conhecimento especializado. Dificuldades de aprendizagem. Paralelismo. Aluno cego. 


\section{INTRODUÇÃO}

Segundo Takimoto (2014), a potencialização da aprendizagem do aluno tem relação direta com a compreensão dos objetos e dos espaços presentes no seu cotidiano. Embora a autora, em seus estudos, tenha focado o aluno cego, entende-se que isso pode ser estendido a todo aluno, tenha ou não qualquer deficiência, pois "a educação especial em uma perspectiva inclusiva surge para oferecer metodologias específicas e que podem ser usadas pelos professores em sala de aula com todos os alunos" (BAPTISTONE et al., 2017, p. 103). Desse modo, o estudo dos temas da Geometria atrelados à questão da localização e da movimentação, dentre os quais se destacam o paralelismo, é importante para atingir esse objetivo.

Destacadamente, quando se fala de paralelismo, evoca-se a ideia de retas e planos paralelos; entretanto, a conceitualização desses entes geométricos em si já forma um obstáculo ao entendimento de suas posições relativas, pois as retas são apresentadas como elementos unidimensionais que se estendem ao infinito. Similarmente, o plano se estende ao infinito em duas dimensões. Por conseguinte, uma possível dificuldade do aluno que perpassa por esse conteúdo da geometria é entender que, quando se fala de retas ou planos paralelos, não se restringe ao que é representado no desenho, mas se vai além do representado, estendendo-se ao infinito. Essa associação com o infinito, um conceito matemático "abstrato, contrário à intuição, bastante complexo à compreensão humana" (MONTEIRO; MONDINI, 2019, p. 31), é um obstáculo possível à construção da conceitualização do aluno sobre o tema paralelismo.

Na Base Nacional Comum Curricular - BNCC (BRASIL, 2018), o paralelismo é considerado explicitamente no 40 ano, correlacionando os objetos de conhecimento do tema com a habilidade de:

(EF04MA16) Descrever deslocamentos e localização de pessoas e de objetos no espaço, por meio de malhas quadriculadas e representações como desenhos, mapas, planta baixa e croquis, empregando termos como direita e esquerda, mudanças de direção e sentido, intersecção, transversais, paralelas e perpendiculares. (BRASIL, 2018, p. 291)

Esse conhecimento intuitivo a que está associado o paralelismo (também na BNCC) é de fundamental importância para entender o que se refere ao deslocamento (obviamente também no caso dos alunos cegos) e dá margem para muitas aplicações no cotidiano. A apropriação dessas aplicações pelo aluno, necessitam da mediação do professor (VYGOTSKY, 1997) demandando vincular o seu conhecimento matemático a práticas pedagógicas capazes de facilitar a aprendizagem matemática do aluno, como, por exemplo, saber que uma possível aplicação de paralelismo é a analogia entre as bordas de uma rodovia e retas paralelas ou as linhas do trem. Ambas estão no mesmo plano, não se cruzam; e, para efetuar uma representação dessa aplicação do significado de linhas paralelas em um pedaço de papel (a folha de sulfite), é necessário efetuar uma redução para além da abstração, de maneira a que essas bordas de uma rodovia ou linhas de trem venham a caber nele.

Ademais, o conhecimento demandado envolve idiossincrasias, quando se trata de um aluno cego, como, por exemplo, saber que o alcance do seu modo de ver se restringe ao que seus dedos podem transmitir ao seu cérebro ou ao que 
ele constrói segundo o que Ihe é dito; assim, ele monta um "quebra-cabeça", construindo o geral com base nas partes (FERNANDES; HEALY, 2006). As dificuldades decorrentes, como a necessidade desse aluno de um tempo maior para construir suas conceitualizações, aliadas ao fato de o professor buscar/criar recursos para fomentar a aprendizagem do aluno com deficiência, fundamentam o discurso de muitos profissionais da educação que afirmam não se sentirem aptos a lidar com esses alunos (FERNANDES; HEALY, 2007).

Essa sensação de inaptidão lança dúvidas quanto ao efetivo cumprimento do que preconiza o Art. 28 no inciso X, da lei da 13.146 (2015), concernente à necessidade de os professores em formação terem acesso a práticas inclusivas. Esse aparente descumprimento do dispositivo legal mencionado vai ao encontro do que apontam várias pesquisas com respeito ao ciclo vicioso que se inicia na sensação de despreparo dos professores e culmina com a formação inadequada dos alunos em todos os níveis de ensino (ver, por exemplo, ALMOULOUD et al., 2004; BARBOZA; CORTELA, 2018; FERREIRA; SADDO, 2017).

O mencionado despreparo é entendido por Barboza e Cortela (2018) como o resultado de "lacunas formativas" (p. 420), que envolvem a falta de contato do futuro professor, durante sua formação acadêmica, com tópicos da Geometria que deverão ser trabalhados com seus futuros alunos. Apreende-se que esse conceito pode ser estendido também a questões de inclusão, uma vez que há uma falta de contato generalizada dos futuros professores com contextos e/ou simulações que lhes permitam desenvolver um conhecimento especializado propiciando, posteriormente desenvolverem práticas inclusivas com todos os seus alunos.

Em consonância, pesquisas destacam a intrínseca relação entre a aprendizagem do aluno e o conhecimento do professor (RIBEIRO, 2011) e tomam esse conhecimento - assumido como especializado e considerado na perspectiva do Mathematics Teachers' Specialized Knowledge ${ }^{1}$ - MTSK (CARRILLO et al., 2018) - como um marco decisivo na aprendizagem discente e considerado como um recurso fundamental à prática matemática docente. Essa especialização incorpora o domínio tanto do conhecimento matemático quanto do conhecimento pedagógico.

Dentre as especificidades da atuação docente, que busca levar os alunos a entender o que fazem e por que o fazem a cada momento, inclui-se o conhecimento das dificuldades de aprendizagem dos alunos em cada um dos tópicos matemáticos a abordar. Esse conhecimento do professor é essencial para que as dificuldades dos alunos sejam minoradas. Nesse trabalho, assume-se o termo dificuldade de aprendizagem, segundo a perspectiva Kauark e Silva (2008): obstáculo resultante da não apropriação de conceitos necessários a compreensão do tema em pauta e não consequente de qualquer debilidade física ou cognitiva.

Diante do pressuposto, frisa-se a questão fomentadora desta discussão: Que conhecimento especializado revelam futuros professores da Educação Infantil e dos Anos Iniciais sobre as dificuldades de aprendizagem dos alunos a respeito do tópico "paralelismo" em contextos que congreguem alunos cegos e videntes? 


\section{FUNDAMENTAÇÃO TEÓRICA}

Apresenta-se aqui o Mathematics Teachers' Specialized Knowledge (MTSK) como referencial teórico que fundamenta as análises do escopo deste artigo. Focam-se, em maior detalhe, os subdomínios que se referem ao conhecimento a respeito do paralelismo e das dificuldades dos alunos na aprendizagem desse tema. Nesta discussão incluem-se também dimensões desse conhecimento na perspectiva de sua ampliação para possibilitar o posterior trabalho também com alunos cegos.

A formação do professor que ensina Matemática (PEM) é o primeiro passo para sua atuação docente. É quando ele se equipa de conhecimentos que se tornarão recursos em sua prática; entretanto, entende-se que essa formação inicia-se junto com sua vida escolar, como aluno da Educação Infantil, pois nesse contexto o futuro professor tem seu primeiro contato com conteúdos da Matemática que se tornarão o lastro sobre o qual se constrói seu conhecimento como PEM (JULIO; SILVA, 2018), e essas experiências moldam, ainda, a sua forma de entender a matemática e o seu ensino (RIBEIRO, 2010).

O conhecimento do professor é o ponto essencial para a aprendizagem do aluno. E destaca-se pelo fato de ter, por função precípua, promover a aprendizagem matemática de terceiros, contrapondo-se ao uso instrumental da matemática que é praticado por outras áreas (RIBEIRO, 2011). Em decorrência dessa circunstância de modo a melhor entender, aceder e/ou avaliar têm sido desenvolvidas diversas conceitualizações - em função da perspectiva assumida desse conhecimento do professor, em particular do PEM (por exemplo, BALL; THAMES; PHELPS, 2008; CARRILLO et al., 2018).

Uma dessas conceitualizações que assume todo o conhecimento do PEM como especializado refere-se ao MTSK (CARRILLO et al., 2018), que considera, no conhecimento do professor, dois domínios e seis subdomínios não hierarquizados. Os dois domínios referem-se ao Pedagogical Content Knowledge (PCK), que versa sobre aspectos de ensino; e ao Mathematical Knowledge (MK), que envolve os aspectos constituintes do conhecimento matemático. Consideram-se ainda as crenças do professor como elemento que perpassa por ambos os domínios e norteia sua prática.

Cada um dos dois domínios do conhecimento se subdivide em três (Figura 1): no MK, reúnem-se: Knowledge of Topics (KoT), Knowledge of the Structure of Mathematics (KSM) e Knowledge of the Practice of Mathematics (KPM); o PCK subdivide-se em: Knowledge of Features of Learning Mathematics (KFLM), Knowledge of Mathematics Teaching (KMT) e Knowledge of Mathematics Learning Standards (KMLS).

Entende-se que a evidência da robustez do Conhecimento Especializado é diretamente proporcional à quantidade de subdomínios abrangidos em sua análise, porém não seria possível, neste recorte, expandi-la a todos os seis subdomínios que configuram as especificidades do conhecimento do professor pedagogo e do licenciado em Matemática. Logo, neste artigo, a análise restringese aos subdomínios KoT, do MK, e KFLM, do PCK, pois, sendo esta uma pesquisa em Educação Matemática, não se poderia esquivar de discutir o conhecimento matemático, ao mesmo tempo que a abordagem da inclusão conduz ao conhecimento subjacente do professor, quanto às especificidades da 
aprendizagem do aluno cego e do vidente. Enfatiza-se que cada subdomínio congrega uma cadeia de elementos norteadores de sua existência, denominados categorias, que explanam distintas particularidades.

Figura 1 - Mathematics Teachers' Specialized Knowledge

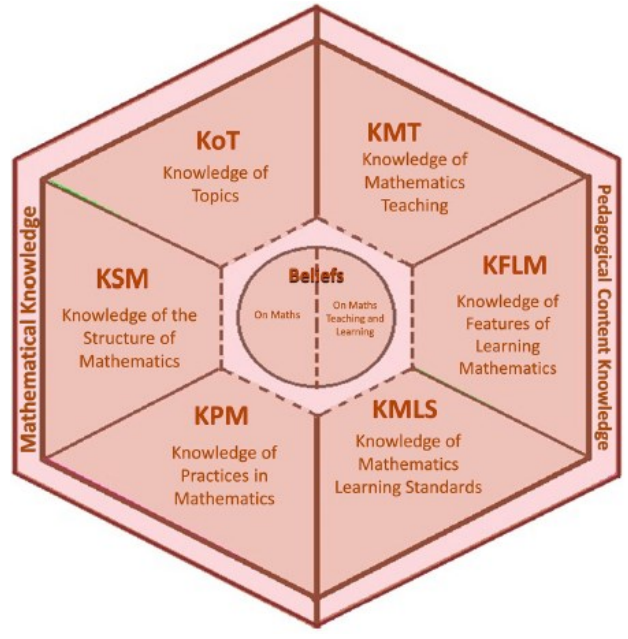

Fonte: Carrillo et al. (2018, p. 241).

Isso posto, esclarece-se que o Knowledge of Topics (KoT) é um dos subdomínios do conhecimento matemático do professor em um nível de aprofundamento e formalismo do tema matemático maior do que o que virá a ser discutido com o aluno. Algumas das suas categorias constituintes são: definições, propriedades, fundamentos, aplicações, registros de representação e procedimentos. Neste trabalho, devido ao foco da pesquisa, dar-se-á atenção às categorias propriedades, aplicações e registros de representação.

Com respeito à categoria propriedades, no tema paralelismo entre retas, o conhecimento do professor envolve, por exemplo, saber que a existência de retas paralelas está atrelada a haver um plano que as contenha, e que serão paralelas se tiverem o mesmo coeficiente angular (com a mesma direção ou inclinação) ou se a distância entre elas for constante (se não se cruzarem); em se tratando de um plano e uma reta, importa saber que caso essa não pertença ao plano (todas as retas são paralelas ao plano que as contém - pois a distância é zero) tem necessariamente de ser paralela a uma reta nele contida.

Destaca-se que, quando se fala de coeficiente angular entre retas, está-se fazendo um estudo de suas posições relativas a partir da perspectiva da Geometria Analítica, que considera a direção/inclinação da reta segundo a tangente do seu ângulo com o eixo das abcissas; portanto, o plano em questão é o cartesiano. Por sua vez, quando se alude à questão da equidistância, analisa-se sua posição relativa segundo a perspectiva da Geometria Euclidiana; logo, para que exista o paralelismo, necessário se faz haver um plano comum às retas analisadas.

Com respeito às aplicações (no contexto matemático e fora dele) importa saber que na matemática o paralelismo se relaciona às propriedades de algumas figuras planas, cujos lados são paralelos dois a dois, a exemplo dos paralelogramos e do que se observa nas propriedades de figuras sólidas, cujas faces são paralelas aos pares, como os prismas retangulares. Já no cotidiano, a consideração do paralelismo se dá usualmente de modo intuitivo, ao imaginar 
planos e retas na superfície do ente em apreço e buscar, a partir deles, a equidistância em toda a sua extensão em relação ao outro - sem que no entanto, normalmente se considere o caso da distância poder ser zero. Desse modo, podese dizer que dois cubos perfilados são paralelos.

Concernente aos registros de representação, associa-se ao conhecimento do professor saber que há distintas formas de representação, dentre elas: a: iconográfica; a formal ou simbólica; e a textual ou língua natural (DUVAL, 2003). Logo, implica saber que os registros de representação pictóricos envolvem uma codificação que permite a representação de figuras tridimensionais no plano, como um cubo com suas faces e arestas paralelas. As arestas constituintes das faces de lado oposto ao que se visualiza são representadas por tracejados. E na linguagem textual ou língua natural engloba saber que se tem como exemplo para o registro de paralelismo a manutenção da mesma distância entre duas retas de mesma inclinação.

Envolve, ainda, saber que a linguagem formal, também chamada de simbólica ou matemática, caracteriza-se pelo uso da simbologia matemática, que, embora the imponha rigor e formalismo científico, também a universaliza. Sua função precípua é sintetizar informações, com vistas a facilitar a conceitualização (CEDRAN; KIOURANIS, 2019). A essas simbologias se atribuem valores linguísticos que permitem a decodificação dessa linguagem sintética e universal. Inclui-se, assim, nesta categoria, saber que um exemplo de uma representação iconográfica de paralelismo é o desenho de um cubo, pois suas faces são paralelas duas a duas; e saber que um exemplo de linguagem formal, tomando $s$ e $t$ retas, cada uma constituída por conjunto de infinitos e sucessivos pontos perfilados, é: $\exists s, t \mid s \cap t=\emptyset$ ou $\mathrm{s} \cap \mathrm{t}=\mathrm{s} \cup \mathrm{t}$, ou ainda, $\mathrm{s} / / \mathrm{t}$.

Duval (2003) defende que a construção da conceitualização se dá quando se é capaz de transitar sem embaraços entre, ao menos, duas das distintas formas de registros de representação. Logo, se o futuro professor consegue partir de uma linguagem pictográfica para uma representação em língua natural sobre o tema paralelismo, ele conseguiu a apreensão do tema.

Por sua vez, o Knowledge of Features of Learning Mathematics (KFLM) enquadra-se no conhecimento pedagógico do professor e refere-se ao seu conhecimento sobre as dificuldades do aluno para apropriar-se do tópico em estudo. Desse modo, na categoria pontos fortes e fracos na aprendizagem matemática, no que tange ao paralelismo, configura (ou deverá configurar) o conhecimento do professor saber que, devido à abstração envolvida em entender que a reta e o plano se estendem ao infinito, o aluno - cego ou vidente precisará de ajuda para compreender que o estudo de suas posições relativas não se restringe apenas ao representado no desenho, mas implica ir além dessa representação. Ter ciência desse fato permitirá que o professor mobilize seu conhecimento matemático para pensar em exemplos que auxiliem os alunos a desenvolverem e/ou ampliarem a sua capacidade de abstração no sentido de ir além de ver Geometria com os olhos.

O conhecimento do professor nesse escopo envolve ainda conhecer um conjunto de analogias que tornam possível ajudar os alunos a entender a distinção entre ter um objeto e efetuar a representação desse objeto, como é o caso de, por exemplo, ao efetuar um desenho de uma casa em um pedaço de papel. Com esse ato, ele faz uma representação de uma casa, de forma que caiba 
ali, porém retrata apenas sua existência, e não suas exatas dimensões. O mesmo se passa com a representação da reta e do plano: como suas dimensões transcendem o que pode ser mensurado, o que se faz é uma representação de sua existência que não condiz com suas reais dimensões.

Pesquisas (LOMÔNACO et al., 2000; SANTANA; ALVES; NUNES, 2015) destacam a intrínseca relação entre a apropriação cognitiva prévia do indivíduo, mediante situações vivenciadas, e a construção de uma nova conceitualização. Isso implica que, para todo aluno (cego ou vidente), cada nova aprendizagem lança a base para aprendizagens futuras, por meio da construção de novos conceitos a partir do que já se sabe. Por conseguinte, também compõe o conhecimento do professor na categoria pontos fortes e fracos na aprendizagem matemática sobre paralelismo saber que será mais profícuo para o aluno ajudálo a entender o paralelismo presente em figuras geométricas espaciais, se primeiro auxiliá-lo a conhecer as que as constitui, explorando suas propriedades - dentre elas, a existência ou não de paralelismo.

Para tanto, pode-se lançar mão da visualização como um potencial recurso para a construção da conceitualização. Mais particularmente, pode-se fazer a apreensão operatória, que é a exploração de uma figura através de sua modificação e reorganização. Dentre os seus três tipos característicos, foca-se aqui a atenção para a apreensão operatória mereológica. Esse recurso da visualização baseia-se no processo exploratório de uma figura que pode ser dividida "em partes que sejam como várias subfiguras, incluí-la em outra figura de modo que ela se torne uma subfigura [...] ela se faz em função da relação parte todo" (DUVAL, 2012, p. 125). Esse processo exploratório permite ao aluno, vidente ou não, construir sua conceitualização. E tem muita semelhança com o modo particular de ver do aluno cego, que principia das partes para o todo (FERNANDES; HEALY, 2006).

Logo, constitui ainda o conhecimento do professor na categoria pontos fortes e fracos na aprendizagem matemática sobre paralelismo saber que a apreensão operatória mereológica é um recurso potencial para explorar o paralelismo em entes geométricos que possuam duas ou três dimensões; e que esse recurso pode, simultaneamente, ser explorado por alunos cegos e videntes.

Com respeito à categoria formas de interação com o conteúdo matemático, o conhecimento do professor implica que ele saiba que a principal forma de interação do aluno vidente com o conteúdo é através dos seus sentidos, especialmente por meio dos sistemas auditivo e visual, porém, no aluno cego, por adaptação, essa relação está centrada nos seus sistemas háptico ${ }^{2}$, auditivo e fonador. Desse modo, também integra o conhecimento do professor, na categoria formas de interação com o conteúdo matemático quanto ao tema paralelismo, saber que, aliando material tátil, como figuras em alto-relevo, com a verbalização do que Ihe for novo (NUNES; LOMÔNACO, 2008), é possível propiciar ao aluno cego oportunidades de montar um conjunto de conhecimentos que lhe permitirá seguir em sua busca pela aprendizagem, explorando esse tema.

O conhecimento do PEM é revelado por meio de indicadores que podem apresentar-se nas produções escritas ou orais sob a forma de evidências, indícios ou oportunidades (ESCUDERO-ÁVILA et al., 2016). Evidências são a presença incontestável do indicador do conhecimento revelado através de uma citação ou 
registro escrito de modo direto, como quando o professor se refere à manutenção da mesma distância entre retas como um fator que lhe permite constatar o paralelismo entre elas.

Indícios são a possibilidade de existência do conhecimento do PEM, inferida a partir do indicador, com base em palavras, questionamentos ou mesmo atos do professor, como quando ele identifica o registro de representação de uma figura como um quadrado. Nesse caso, infere-se que ele conhece algumas das propriedades do quadrado: possuir quatro lados, ter seus lados paralelos dois a dois e possuir quatro ângulos retos. Entretanto, sem uma intervenção (a exemplo de perguntas direcionadas), não há como saber quais propriedades ele conhece.

Por sua vez, oportunidades são rápidas incursões que o professor faz por conteúdos matemáticos correlatos ao tema discutido, como quando, em meio ao conteúdo de paralelismo, o professor fala que retas paralelas não são concorrentes por não se cruzarem. Uma vez que retas concorrentes formam, junto com as paralelas e as reversas, duas dentre as possíveis posições relativas entre retas, há nesse momento uma oportunidade de falar rapidamente sobre esse conteúdo que foi ou ainda será objeto de discussão com os alunos.

\section{CONTEXTO E MÉTODO}

Este texto integra uma pesquisa mais ampla, que tem por foco o Conhecimento Especializando de futuros professores da Educação Infantil e dos Anos Iniciais no âmbito das posições relativas das retas. Aqui, faz-se um recorte, focando esse conhecimento no que se refere aos tópicos e às dificuldades de aprendizagem dos alunos no âmbito do paralelismo. Para isso, foi implementada uma tarefa formativa (RIBEIRO, 2016), em uma das 15 aulas de 4 horas, em um grupo de 28 futuros professores que frequentavam o 3 o ano do curso de Pedagogia de uma universidade pública do estado de São Paulo, Brasil. Desenvolveu-se, assim, um estudo de caso instrumental (STAKE, 1995) com uma abordagem interpretativa, buscando contribuir com algumas teorizações que nos permitam avançar para além do caso particular estudado.

Por ser um contexto formativo e todas as tarefas formativas que desenvolvemos ${ }^{3}$ terem explicitamente associadas e de forma imbricada a dimensão da formação e a da pesquisa, a tarefa que aqui se discute compunha-se de três partes complementares, desenhadas com o intuito de aceder- e desenvolvê-lo - ao Conhecimento Especializado de futuros professores da Educação Infantil e dos Anos Iniciais sobre o tema paralelismo.

A Parte I focava-se nas definições, nas propriedades, nas aplicações, nos procedimentos e nos registros de representação no âmbito do paralelismo; a Parte II, tendo como ponto de partida uma simulação de um contexto com potencial de fomentar discussões matemáticas com alunos cegos e videntes simultaneamente, objetivava contribuir para desenvolver o conhecimento dos futuros professores no âmbito das propriedades, das aplicações, dos registros de representação e das dificuldades de aprendizagem sobre o tema paralelismo, discutindo em particular os obstáculos à aprendizagem dos alunos; a Parte III buscava contribuir para um melhor entendimento do conhecimento dos futuros professores sobre o tema, ao atribuírem significado a produções de alunos 
videntes e cegos, tendo em conta conexões com outros temas, dificuldades de aprendizagem, definições e propriedades.

Desse modo, nos itens "a" e "b" apresentam-se duas retas, para que, pela associação do tato com o seu conhecimento prévio das propriedades de retas paralelas, concluíssem se elas são ou não paralelas (NUNES; LOMÔNACO, 2008). Partindo do mesmo princípio, no item " $c$ ", representam-se três planos sobrepostos, em que o tracejado simboliza uma sobreposição e o pontilhado, uma dupla sobreposição. A ideia desse item foi ajudá-los a refletir sobre as maiores dificuldades do aluno para entender o paralelismo no âmbito espacial. 0 item " $d$ " novamente os convida a refletir sobre as dificuldades dos alunos, dessa vez, para apropriar-se do tema paralelismo no âmbito tridimensional, quando representado no plano. Elegeu-se para esse fim o desenho de dois cubos, pois essa figura geométrica tem, como uma de suas propriedades, o paralelismo entre as suas faces opostas e também nos lados opostos de cada uma das faces que o constituem.

Figura 2 - Segunda parte da tarefa

Parte II
Identifique as figuras que lhe forem entregues e justifique se podem ou não ser consideradas
representações de "coisas" paralelas ou perpendiculares. Peça que o assistente registre suas
constataços.

a)

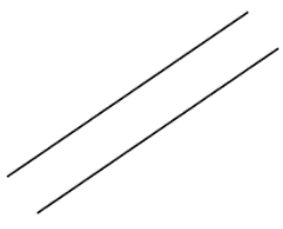

c)

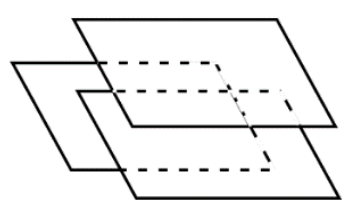

b)

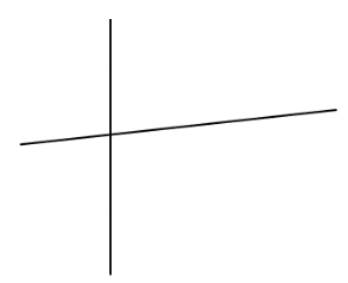

d)

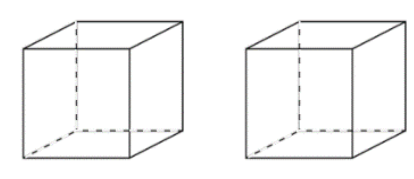

Fonte: Autoria própria (2017).

Para cumprir os propósitos descritos, cada item desta parte da tarefa foi lançado em alto-relevo em cartão confeccionado em papel de gramatura maior que a do papel sulfite (Figura 3), em quantidade suficiente para que todos os participantes tivessem acesso simultâneo ao item da vez.

Figura 3 - Cartão com um item da Parte II

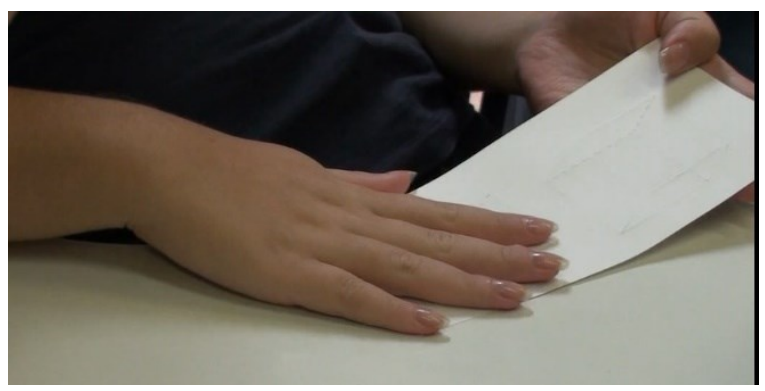

Fonte: Acervo da pesquisa (2018). 
A dinâmica de implementação da tarefa constituiu-se na formação de grupos compostos por quatro integrantes cada - escolhidos pelos próprios estudantes. Cada parte da tarefa foi entregue apenas após a conclusão da parte precedente por todos os grupos, e as discussões em cada grupo foram gravadas em vídeo e áudio. Na parte da tarefa que se discute aqui (Parte II - veja-se Figura 2), foram dadas instruções para que, em cada item, fosse designado um relator, que seria o único a ficar sem máscara e assumiria um papel operacional -responsável pelo registro dos comentários e das respostas dos demais elementos do grupo e não poderia dar pistas ou responder a perguntas, pois toda a discussão deveria ser feita apenas pelos que estavam temporariamente privados da visão.

Para a dinamização, cada membro do grupo recebeu um cartão como o da Figura 3, contendo o item da vez, e apenas pela exploração tátil (recorde-se que estavam vendados) deveriam identificar o que se encontrava representado. Cabia ao relator registrar o que considerava essencial das discussões ocorridas. No final de cada discussão retiravam a máscara e observavam a representação que tentaram identificar.

Aqui se foca no conhecimento revelado pelos futuros professores, nas resoluções da Parte II da tarefa (Figura 2), constituída por quatro itens (de "a" a " $d$ "), que, em conjunto, exploram o paralelismo, partindo do unidimensional para o tridimensional. Destacadamente, devido ao potencial para discussão que emergiu da análise, aliado à necessidade de respeitar o espaço delimitado para este trabalho, apresentam-se no tópico seguinte a análise e a discussão de todos os itens, porém dá-se especial atenção ao "d". Para a análise, foram efetuadas as transcrições das discussões dos grupos e consideraram-se as respectivas produções escritas, tendo sido atribuídos nomes fictícios a cada um dos participantes. Aqui, por uma questão de espaço, discutem-se as informações de dois dos grupos, que se mostraram mais relevantes para a discussão que se pretende elaborar. Para a transcrição, cada linha (identificadas numericamente entre colchetes) corresponde à fala dos futuros professores. O vídeo complementou a transcrição do áudio, sempre que foi necessário para compreender o raciocínio elaborado: a indicação de gestos e/ou a apresentação de algum objeto tiveram sua descrição entre parênteses. Como exemplo de complementação apresenta-se a Figura 4.

Figura 4 - Exemplo de complemento de transcrição

[1] Eva: é que esse daqui (apontando para a representação pictórica que está na parte inferior da imagem 2)

Fonte: Acervo da pesquisa (2018).

Nota-se que, na situação transcrita na Figura 4, a participante aponta para um dos registros de representação que acabara de fazer (Figura 5). Em situações desse tipo, sem a descrição entre parênteses, não seria possível compreender a que ela se refere. 


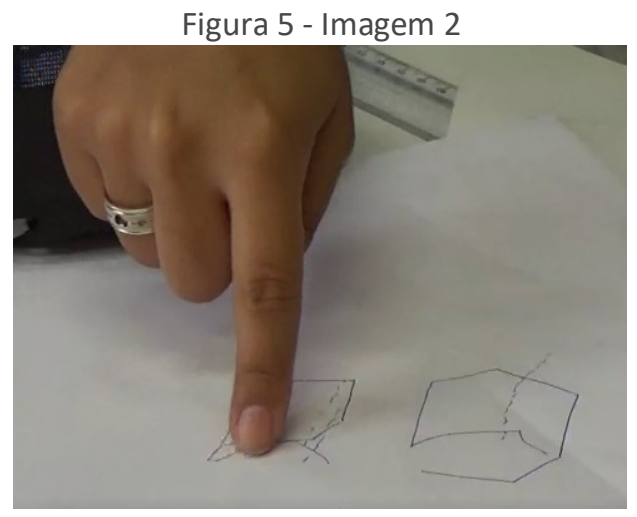

Fonte: Acervo da pesquisa (2018).

Esses dados foram analisados recorrendo à lente do Mathematics Teachers' Specialized Knowledge (MTSK), na busca de evidências, indícios ou oportunidades de indicadores do conhecimento especializado desses futuros professores, no âmbito dos subdomínios Knowledge of Topics (KoT) e Knowledge of Features of Learning Mathematics (KFLM). Os indicadores identificados receberam um acrônimo composto pela sigla do subdomínio em questão, acrescido da(s) letra(s) representativa(s) da categoria associada e seguido de um número sequencial. Assim, por exemplo, para a primeiro indicador de conhecimento relativo a Propriedades, que corresponde a um conhecimento dos Tópicos, usamos o acrónimo KoTP1. De um modo geral os acrônimos decorrentes são do tipo que se apresenta no Quadro 1:

Quadro 1 - Descrição dos acrônimos

\begin{tabular}{|c|c|c|}
\hline Subdomínio & Categoria & Acrônimo \\
\hline \multirow{3}{*}{ KoT } & Propriedades & KoTP1 \\
\cline { 2 - 3 } & Aplicações & KoTA1 \\
\cline { 2 - 3 } & Registros de representação & KoTRR1 \\
\hline \multirow{2}{*}{ KFLM } & Pontos fortes e fracos na aprendizagem matemática & KFLMPff1 \\
\cline { 2 - 3 } & Formas de interação com conteúdo & KFLMFi1 \\
\hline
\end{tabular}

Fonte: Autoria própria (2018).

Ressalta-se que a numeração sequencial não se associa à priorização de determinados indicadores de conhecimento (em sua categoria) em detrimento de outros, mas apenas revela a ordem em que esses foram aparecendo na análise.

\section{ANÁLISE E DISCUSSÃO}

No cômputo geral, os futuros professores buscaram respostas imediatas para os problemas propostos, focando em visualizar o objeto como um todo, mas também houve os que tentaram construí-lo a partir de um levantamento de suas propriedades, praticando o que DUVAL (2012) denomina de apreensão operatória mereológica, o que evidencia seu conhecimento sobre paralelismo no âmbito do subdomínio KoT. Desse modo, pode-se afirmar que todos responderam os problemas e alguns revelaram um aprofundamento maior do 
seu conhecimento. Entretanto, fez-se necessário buscar atingir o refinamento desse conhecimento durante as discussões.

Os futuros professores revelaram saber que as retas paralelas têm a mesma direção e não se cruzam (KoTP1). Provavelmente, por se tratar de elementos unidimensionais, essa percepção foi quase imediata. Ressalta-se que nem a produção escrita (Quadro 2) nem as discussões fomentadoras dão subsídios para afirmar se os futuros professores tinham ciência de que as afirmações "têm a mesma direção" e "não se encontram" vêm de perspectivas distintas: a primeira, da Geometria Analítica; e a segunda, da Geometria Euclidiana.

Quadro 2 - Produção relacionada ao item "a"

\section{a) Podem ser considerados paralelas, pais elas

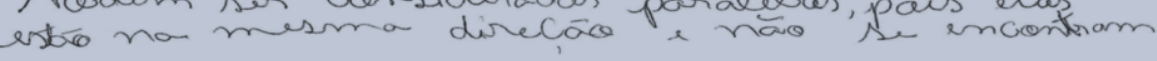 \\ a) Podem ser consideradas paralelas, pois elas estão na mesma direção e não se encontram.}

Fonte: Acervo da pesquisa (2018).

Similarmente, os futuros professores revelaram seu conhecimento, ao afirmar que as retas em apreço, nas produções do item "b)", não eram paralelas ou perpendiculares (Quadro 3). Demonstraram conhecer as propriedades envolvendo ambas as posições relativas, por sua afirmação: "As retas se cruzam formando um ângulo diferente de $90^{\circ}$ ". Desse modo evidenciaram conhecer que retas paralelas não se cruzam (KoTP1).

Quadro 3 - Produção relacionada ao item "b"

b) (sós sāo paralelas nem perpendiculares. As. retas se cruzam formando ânguios diferentes de $90^{\circ}$.

b) Não são paralelas nem perpendiculares. As retas se cruzam formando ângulos diferentes de $90^{\circ}$.

Fonte: Acervo da pesquisa (2018).

As produções escritas, ao afirmarem, no item "c)", "esse é diferente" (Quadro 4), ainda mostraram um impacto inicial por não serem elementos unidimensionais, mas sim figuras bidimensionais; por conseguinte, houve dificuldade para apreenderem do que se tratava. Apesar disso, conseguiram identificar a existência de um quadrilátero que chamaram de retângulo. Quando se observa o problema proposto (item "c)" na Figura 2, nota-se serem três paralelogramos sobrepostos. Entretanto, há de se considerar que os futuros professores estavam de olhos vendados, e essa foi sua primeira experiência, nessa condição, com uma representação espacial. 
Quadro 4 - Produção relacionada ao item "c"

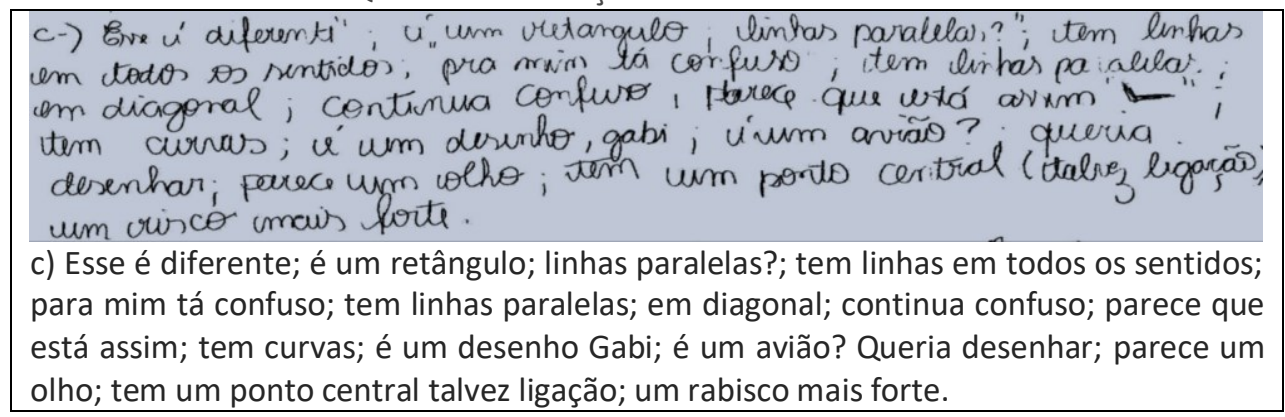

Fonte: Acervo da pesquisa (2018).

Percebe-se ainda que, na busca por uma solução ao problema, mesmo tendo afirmado ser um retângulo, os professores procuraram elementos para subsidiar sua solução e se depararam com "linhas paralelas". Embora confusos com esse primeiro contato com a representação do bidimensional no espaço, identificaram-nas como lados de um retângulo e revelaram evidências de saber que retângulos possuem lados opostos paralelos (KoTP2).

No Quadro 5, ao reportarem "Não sei o que é, mas tem um quadrado. São duas figuras", notam-se indícios do seu conhecimento sobre as propriedades de um quadrado, denotando saber que possui quatro lados paralelos dois a dois e quatro vértices que formam ângulos retos (KoTP1). Destacar o paralelismo entre seus lados opostos corresponde a conhecer que o paralelismo está presente em figuras bidimensionais (KoTA1).

Quadro 5 - Produção pautada na apreensão operatória

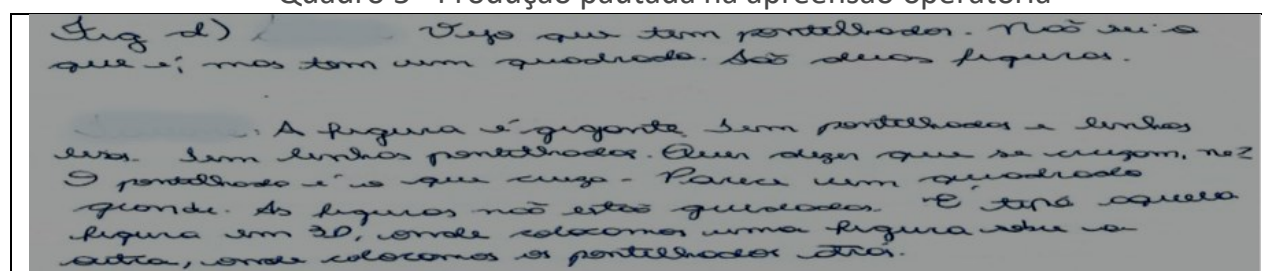

Figura d) Vejo que tem pontilhados. Não sei o que é, mas tem um quadrado... São duas figuras.

A figura é gigante. Tem pontilhados e linhas leves. Tem linhas pontilhadas. Quer dizer que se cruzam, né? o pontilhado é o que cruza. Parece um quadrado grande. As figuras não estão grudadas. É tipo aquela figura em 3D, onde colocamos uma figura sobre a outra, onde colocamos os pontilhados atrás.

Fonte: Acervo da pesquisa (2018).

Nota-se ainda que os docentes conseguiram associar seu conhecimento sobre figuras geométricas ao que tatearam (viram por meio dos seus dedos) e aventaram ser uma figura tridimensional representada no plano. Isso evidenciou o conhecimento deles sobre o tema matemático na categoria registros de representação, pois, partindo de um registro de representação pictórico, conseguiram fazer a apreensão operatória mereológica da figura e transformá-la num registro de representação em linguagem natural que os remeteu à representação de uma figura tridimensional (KoTRR1).

Além disso, revelaram conhecer registros de representação pictórica, decodificando-a para a linguagem natural, ao afirmarem: "É tipo aquela figura em $3 \mathrm{D}$, onde colocamos uma figura sobre a outra, onde colocamos os pontilhados atrás." Evidenciaram saber que, no registro de representação pictórica, há um 
código para representar uma figura tridimensional no plano (KoTRR2). Esse trânsito livre entre as duas formas de registros de representação é evidência da sua apropriação do tema paralelismo (DUVAL, 2003).Corroborando a ideia do conhecimento sobre as formas de registros de representação, Eva (futura professora), ainda com a máscara que a fazia simular cegueira, fez a transição do apreendido por meio do tato, decodificando-o, formando uma imagem mental (Figura 6). E, lançando mão do desenho como forma de externar o que sabia sobre a figura, fez um registro pictórico a partir dessa decodificação. Isso deu indícios de saber que o desenho (forma pictográfica) é uma forma de registro de representação (KoTRR1).

Figura 6 - Desenho feito pela professora Eva enquanto simulava cegueira

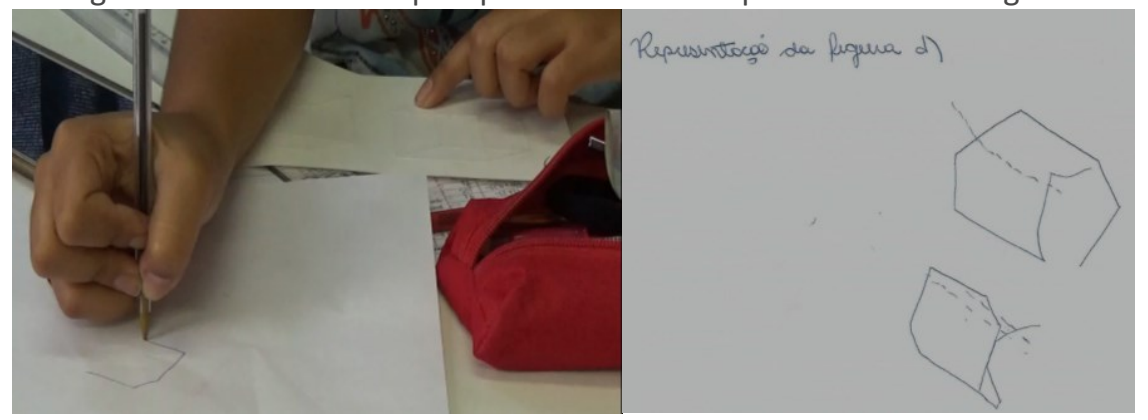

Fonte: Acervo da pesquisa (2018).

No processo resolutivo, percebeu-se que estavam, de fato, explorando a figura das partes para o todo e compondo de forma gradual uma imagem da figura. Isso é a prática da apreensão operatória mereológica, configurando indícios de conhecerem essa prática como um forte aliado na aprendizagem (KFLMFi1), embora não se possa afirmar se sabem seu nome. Essa construção pode ser notada através do diálogo entre componentes de um dos grupos que simularam cegueira (Figura 7):

Figura 7 - Excerto de discussão sobre o item "d"

[1]Flavia: Então, são duas figuras.

[2] Eva: é pode ser duas, mas não sei...

[3] agora estou no meio livre (tateando o espaço entre os dois cubos) ...

[4] aí o... eu passo a mão aqui em cima é pequeno (tateando a parte superior de um dos cubos)

[5] ... sabe o que eu queria? Poder desenhar o que eu tô sentindo...

[6] acho que ficaria muito mais fácil na minha cabeça.

[7]Flavia: é, eu também queria poder desenhar

[8] Dani: desenha ué... quer desenhar aqui ô (colocando uma folha de papel em branco nas mãos de Eva)

[9] Eva: ah vai ficar lindo (em tom irônico)

[10] Dani: tenta desenhar

Fonte: Acervo da pesquisa (2018).

Nota-se uma referência a um quadro mental, quando se afirma, na linha [6] "... acho que ficaria muito mais fácil na minha cabeça", o que coaduna com a ideia da construção de novos conceitos com base no que já se sabe (LOMÔNACO et al., 2000), revelando saber que a composição de uma imagem acessada pelo tato não necessariamente implica em uma descrição verbal ou escrita coerente (KFLMPff1). 
Essa ação, corroborando os estudos de Nunes e Lomônoco (2008), também lança luz à ideia de que, sendo fornecidos ao aluno cego os meios adequados, ele poderá construir sua conceitualização a partir do que já sabe, por meio da exploração tátil do que lhe é apresentado. Logo, o conhecimento dos futuros professores dá indícios de saber que a apreensão operatória mereológica pode ser usada tanto por cegos quanto por videntes (KFLMPff2).

Em todos os grupos, os integrantes discutiam sobre o que apreendiam pelo tato, e alguns utilizavam sem embaraços o verbo "ver", enquanto outros optavam pelo verbo "sentir". Essas discussões refletiram-se em sua produção escrita, a exemplo do que ilustra o Quadro 5, em que assim se reportam à exploração tátil: "Vejo que tem pontilhados". O emprego do verbo "ver", mesmo quando vendados no decurso das discussões fomentadoras e nas produções escritas, lança indícios de saberem que o uso do sistema háptico é um modo particular de ver, praticado pelo aluno cego, que constrói a imagem da parte para o todo (KFLMFi2). Se explorado de forma integrada aos seus sistemas fonador e auditivo na construção da sua conceitualização, pode the fornecer equidade de oportunidade de aprendizagem com o aluno vidente (FERNANDES; HEALY, 2006; NUNES; LOMÔNACO, 2008; VYGOTSKY, 1997).

Os futuros professores revelaram saber que a equidistância é uma das propriedades do paralelismo e demonstraram que se apropriaram da conceitualização do tema, ao transitar entre os registros de representação pictórica e linguagem natural. Entende-se que, ao fazerem uso da apreensão operatória mereológica para solucionar os problemas propostos, os futuros professores, revelaram conhecer essa habilidade como recurso potente para a aprendizagem (mesmo que desconhecessem o nome) e deixaram ver que é na condição de estudantes que lançam a base para o conhecimento que será usado em sua prática como PEM (JULIO; SILVA, 2018). Também o contexto simulativo os ajudou a entender que a forma de interação do aluno cego com o conteúdo matemático pode ser incrementada pela associação com a verbalização. Apresenta-se no Quadro 6 uma síntese do conhecimento revelado pelos futuros professores da Educação Infantil e dos Anos Iniciais.

Quadro 6 - Síntese do conhecimento especializado dos futuros professores da Educação Infantil e dos Anos Iniciais sobre paralelismo em uma simulação de contexto inclusivo

\begin{tabular}{|c|c|c|}
\hline Subdomínio & & Conhecimentos \\
\hline \multirow{6}{*}{ КоТ } & \multirow{3}{*}{ Propriedades } & $\begin{array}{l}\text { KoTP1: saber que retas paralelas possuem a mesma } \\
\text { direção / não se cruzam }\end{array}$ \\
\hline & & $\begin{array}{l}\text { KoTP2: saber que retângulos (quadrados) têm quatro } \\
\text { lados paralelos dois a dois e quatro ângulos retos }\end{array}$ \\
\hline & & KoTP3: saber que retas paralelas são equidistantes \\
\hline & Aplicações & $\begin{array}{l}\text { KoTA1: saber que os lados opostos de um quadrado } \\
\text { são paralelos }\end{array}$ \\
\hline & \multirow{2}{*}{$\begin{array}{l}\text { Registros de } \\
\text { Representação }\end{array}$} & $\begin{array}{l}\text { KoTRR1: saber navegar entre a representação } \\
\text { pictórica (a representação de uma figura } \\
\text { tridimensional no plano, o cubo como exemplo) para } \\
\text { a linguagem natural (figura em 3D) e vice-versa }\end{array}$ \\
\hline & & $\begin{array}{l}\text { KoTRR2: saber que, por meio do uso de linhas } \\
\text { tracejadas intercaladas com linhas cheias } \\
\text { (codificação), é uma das possíveis formas de efetuar } \\
\text { uma representação de uma figura tridimensional no } \\
\text { plano }\end{array}$ \\
\hline
\end{tabular}




\begin{tabular}{|c|c|c|}
\hline \multirow{4}{*}{ KFLM } & \multirow{2}{*}{$\begin{array}{l}\text { Pontos fortes } \\
\text { e fracos na } \\
\text { aprendizagem } \\
\text { matemática }\end{array}$} & $\begin{array}{l}\text { KFLMPff1: saber que conseguir identificar através do } \\
\text { tato o paralelismo não implica dizer que saberá fazer } \\
\text { corretamente um registro de representação ou } \\
\text { mesmo uma descrição }\end{array}$ \\
\hline & & $\begin{array}{l}\text { KFLMPff2: saber que a exploração da apreensão } \\
\text { operatória mereológica é um recurso que pode ser } \\
\text { usado pelos cegos e videntes }\end{array}$ \\
\hline & \multirow{2}{*}{$\begin{array}{l}\text { Formas de } \\
\text { interação com } \\
\text { o conteúdo } \\
\text { matemático }\end{array}$} & $\begin{array}{l}\text { KFLMFi1: saber que o uso da apreensão operatória } \\
\text { mereológica é um potencializador da aprendizagem } \\
\text { sobre paralelismo }\end{array}$ \\
\hline & & $\begin{array}{l}\text { KFLMFi2: saber que o modo particular de ver do cego } \\
\text { segue o princípio parte-todo. }\end{array}$ \\
\hline
\end{tabular}

Fonte: Autoria própria (2018).

Nota-se que os indicadores do Conhecimento Especializado pelos futuros professores da Educação Infantil e dos Anos Iniciais revelaram-se bastante equilibrados entre as categorias dos subdomínios KoT e KFLM analisadas, apenas as categorias aplicações e propriedades apresentaram quantidade diferentes de dois indicadores.

\section{CONSIDERAÇÕES FINAIS}

A pesquisa em tela lançou luz sobre o conhecimento do professor quanto ao paralelismo em meio a um contexto de práticas simuladas de inclusão, em que as tarefas formativas foram desenhadas com o objetivo explícito de aceder ao conhecimento especializado dos futuros professores e, pela formação, desenvolvê-lo (RIBEIRO, 2011). Podem-se observar indícios de que sabem que o paralelismo se aplica a figuras bidimensionais, como o quadrado; conhecem a apreensão operatória mereológica como um potencial aliado para a aprendizagem do paralelismo; e percebem que o modo de ver do cego se baseia na construção de partes para formar o todo, o que permite e potencializa o uso da apreensão operatória mereológica na construção de sua conceitualização sobre o tema.

Na mesma linha, obtiveram-se evidências de que conhecem as formas de registros de representação pictórica e linguagem natural, transitando livremente entre elas, o que implica em ter uma conceitualização sobre o tema "paralelismo" já estabelecida (DUVAL, 2003). As análises evidenciaram, ainda, que sabem que, para haver paralelismo entre retas, elas devem ser equidistantes e que é possível fazer a representação de figuras tridimensionais no plano.

Esses indícios e evidências do Conhecimento Especializado do Professor em práticas simuladas de inclusão são refentes aos subdomínios Knowledge of Topics (KOT) e Knowledge of Features of Learning Mathematics (KFLM). No primeiro deles, eles se referem à categoria registros de representação, pois os professores conseguiram transitar livremente entre o registro de representação de um cubo na forma pictográfica e em linguagem natural, identificaram características da representação de uma figura tridimensional no plano e ainda em aplicações, porque entenderam que há paralelismo nos lados opostos de um quadrado e de um retângulo. 
Já os indícios do KFLM na categoria formas de interação com o conteúdo matemático, residem em saberem que a principal forma de acesso ao conteúdo paralelismo para o aluno cego é o sistema háptico e que o uso da apreensão operatória mereológica é um potencializador na aprendizagem. Por sua vez, a categoria pontos fortes e fracos na aprendizagem matemática foi revelada por saberem que identificar paralelismo não implica em saber representá-lo ou descrevê-lo corretamente e que a forma de ver do aluno cego se embasa na construção da parte para o todo.

Este trabalho perspectiva novas pesquisas para entender melhor o conhecimento do professor com respeito ao ensino de paralelismo em ambientes inclusivos. Nesse sentido, há questões que podem ser temas de trabalhos futuros, com discussões sobre o conhecimento do professor, visando à melhoria da sua prática: (i) o conteúdo e o papel do conhecimento de futuros professores, tomando a visualização por base, ao abordar paralelismo; (ii) o conhecimento especializado revelado por futuros professores, ao atribuírem significado às respostas de alunos sobre a posição relativa de "objetos e entes matemáticos"; e (iii) o conhecimento especializado do futuro professor revelado no ensino sobre o tema paralelismo a alunos cegos. 


\title{
Specialized knowledge of future kindergarten and early years teachers regarding students' learning disabilities about parallelism
}

\begin{abstract}
In this paper we analyze a set of kindergarten and primary prospective teachers productions from the implementation of a task simulating an inclusive environment involving blindness and focusing on the students learning difficulties on the topic of parallelism. Teachers knowledge is perceived here considering the Mathematics Teachers' Specialized Knowledge conceptualization. Results pinpoint prospective teachers' knowledge includes knowing that the mereological operative apprehension ability is a potential resource for the learning of parallelism for both blind students and the seers and that identifying parallelism does not imply knowing how to represent it. Also, analysis allowed to elaborate a list of elements of the content of teachers' knowledge on parallelism.
\end{abstract}

KEYWORDS: Specialized Knowledge. Learning Difficulties. Parallelism. Blind Student. 


\section{AGRADECIMENTOS}

Este texto foi produzido no âmbito do projeto "Conhecimento matemático especializado do professor que ensina Matemática na Educação Infantil e nos Anos Iniciais: um foco em conteúdos de Geometria", processo número 2016/22557-5, com financiamento da Fundação de Amparo à Pesquisa do Estado de São Paulo (FAPESP).

\section{NOTAS}

1 Optou-se por manter a nomenclatura em inglês, pois esta é uma conceitualização do conhecimento especializado do professor reconhecida em nível internacional, e a tradução desvirtuaria não apenas o sentido, mas, essencialmente, o conteúdo de cada um dos subdomínios que compõem o modelo que a representa.

2 É o sistema alimentado pelo tato ativo, a busca intencional de algo pelo tato, envolvendo, além dos receptores de pele e tecidos, os receptores dos músculos e dos tendões (OCHAITA; ROSA, 1995).

${ }^{3}$ As tarefas formativas usadas nos contextos de formação e pesquisa têm por base o trabalho desenvolvido no CIEspMat - Grupo de Pesquisa e Formação de Conhecimento Interpretativo e Especializado do professor de e que ensina matemática.

\section{REFERÊNCIAS}

ALMOULOUD, S. A. et al. Geometria no ensino fundamental: reflexões sobre uma experiência de formação envolvendo professores e alunos. Revista Brasileira de Educação, n. 27, p. 94-108, dez. 2004.

BALL, D. L.; THAMES, M. H.; PHELPS, G. Content Knowledge for Teaching: What makes it special? Journal of Teacher Education, v. 59, n. 5, p. 389-407, 2008.

BAPTISTONE, G. F. et al. A inclusão do aluno cego na educação superior: percepções de professores de um curso de licenciatura em Química. ACTIO: Docência em Ciências, v. 2, n. 1, p. 98-121, jul. 2017.

BARBOZA, A. P. R.; CORTELA, B. S. C. Formação do PNAIC em Geometria e a trajetória educacional dos professores alfabetizadores. Bolema - Boletim de Educação Matemática, Rio Claro, v. 32, n. 61, p. 419-438, ago. 2018.

BRASIL. Base Nacional Comum Curricular. Brasília-DF: Ministério da Educação, 2018.

CARRILLO, J. et al. The mathematics teacher's specialised knowledge (MTSK) model. Research in Mathematics Education, v. 20, n. 3, p. 236-253, set. 2018.

CEDRAN, D. P.; KIOURANIS, N. M. M. Teoria dos Campos Conceituais: visitando seus principais fundamentos e perspectivas para o ensino de ciências. ACTIO: Docência em 
DUVAL, R. Registros de representações semióticas e funcionamento cognitivo da compreensão em Matemática. In: MACHADO, S. D. A. Aprendizagem em matemática: registros de representação semiótica. Campinas: Papirus, 2003. p. 11-33.

DUVAL, R. Abordagem cognitiva de problemas de geometria em termos de congruência. REVEMAT - Revista Eletrônica de Educação Matemática, v. 7, n. 1, p. 118-138, 2012.

ESCUDERO-ÁVILA, D et al. Aportaciones metodológicas de investigaciones con MTSK. In: REFLEXIONANDO SOBRE EL CONOCIMIENTO DEL PROFESOR, 2016, SGSE: Huelva. Anais... SGSE: Huelva: J. Carrillo, L. C. Contreras y M. Montes, 2016. p. 60-68.

FERNANDES, S. H. A. A.; HEALY, L. Mãos que falam; mãos que vêem. O papel do sistema háptico no processo de objetificação do conhecimento matemático por alunos cegos. In: REUNIÃO DE DIDÁTICA DA MATEMÁTICA DO CONE SUL, 7., 2006, Águas de Lindóia. Anais... Águas de Lindóia: PUC São Paulo, 2006. p. 1-13.

FERNANDES, S. H. A. A.; HEALY, L. Ensaio sobre a inclusão na Educaçâo Matemática. Revista Iberoamericana de Educación - Unión, n. 10, p. 59-76, jun. 2007.

FERREIRA, M. B. C.; SADDO, A. A. Análise dos livros de geometria indicados nos cursos de licenciatura em matemática. Revemat: Revista Eletrônica de Educação Matemática, v. 12, n. 2, p. 16-57, 2017.

JULIO, R. S.; SILVA, G. H. G. DA. Compreendendo a formação matemática de futuros pedagogos por meio de narrativas. Bolema - Boletim de Educação Matemática, Rio Claro, v. 32, n. 62, p. 1012-1029, dez. 2018.

KAUARK, F. da S.; SILVA, V. A. dos S. Dificuldades de aprendizagem nas séries iniciais do Ensino Fundamental e ações psico \& pedagógicas. Revista Psicopedagogia, v. 25, n. 78, p. 264-270, 2008.

LOMÔNACO, J. F. B. et al. Desenvolvimento de conceitos: o paradigma das descobertas. Psicologia Escolar e Educacional, v. 42, n. 2, p. 31-39, 2000.

MONTEIRO, G. DE L.; MONDINI, F. Paradoxos falsídicos: os primeiros enfrentamentos do conceito de infinito no contexto da ciência matemática. ACTIO: Docência em Ciências, v. 4, n. 2, p. 30-47, ago. 2019.

NUNES, S. S.; LOMÔNACO, J. F. B. Desenvolvimento de conceitos em cegos congênitos: caminhos de aquisição do conhecimento. Revista Semestral da Associação Brasileira de Psicologia Escolar e Educacional (ABRAPEE), v. 12, n. 1, p. 119-138, jun. 2008.

OCHAITA, E.; ROSA, A. Percepção, ação e conhecimento nas crianças cegas. Desenvolvimento psicológico e Educação: necessidades educativas especiais e aprendizagem escolar. Porto Alegre: Artes Médicas, 1995. v. 3. p. Cap. 12.

RIBEIRO, M. A importância do conhecimento do conteúdo matemático na prática letiva de uma professora: discutindo um modelo de análise. Zetetiké, v. 19, n. 35, p. 71-102, 
RIBEIRO, M. O desenvolvimento profissional de duas professoras do $1^{\circ} \mathrm{Ciclo}$, envolvidas num grupo de trabalho colaborativo, partindo da modelação das suas aulas de matemática. 2010. 656 f. Tese de Doutorado em Educação MatemáticaUniversidade de Huelva, Espanha, 2010.

RIBEIRO, M. Tareas para alumnos y tareas para la formación: discutiendo el conocimiento especializado del profesor y del formador de profesores de matemáticas. In: XX JORNADAS NACIONALES DE EDUCACIÓN MATEMÁTICA - SOCHIEM, 2016, Valparaíso: Chile. Anais... Valparaíso: Chile: [s.n.], 2016. p. 31-39.

SANTANA, E.; ALVES, A. A.; NUNES, C. B. A Teoria dos campos conceituais num processo de formação continuada de professores. Bolema - Boletim de Educação Matemática, Rio Claro, v. 29, n. 53, p. 1162-1180, dez. 2015.

STAKE, R. E. The art of case study research. 1. ed. Thousand Oaks, CA: Sage, 1995.

\section{TAKIMOTO, T. A percepção do espaço tridimensional e sua representação}

bidimensional: a geometria ao alcance das pessoas com deficiência visual em comunidades virtuais de aprendizagem. 2014. 161 f. Dissertação (Mestrado em Engenharia e Gestão do Conhecimento) - Universidade Federal de Santa Catarina, Florianópolis, 2014.

VYGOTSKY, L. Obras escogidas: Fundamentos de defectologia. Madrid: Visor Dis, 1997. v. 5.

COUTO, S.; RIBEIRO, M. Conhecimento especializado de futuros professores da educação infantil e dos anos iniciais quanto às dificuldades de aprendizagem de alunos cegos e videntes sobre paralelismo. ACTIO, Curitiba, v. 4, n. 3, p. 701-721, set./dez. 2019. Disponível em: https://periodicos.utfpr.edu.br/actio. Acesso em: XXX 